\title{
Application of imperialist competitive optimization algorithm in power industry
}

\author{
Mohammad Shahrazad and Amir Hessam Alikhanzadeh*
}

Department of Electrical Engineering, Brunel University, London, UK

\begin{tabular}{l}
\hline C H R O N I C L E \\
\hline Article history: \\
Received July 62014 \\
Received in Revised Format \\
September 92014 \\
Accepted September 102014 \\
Available online \\
September 12 2014 \\
\hline Keywords: \\
Imperialist Competitive Algorithm \\
FACTS Devices \\
Optimization \\
Evolutionary Algorithms \\
Total Transfer Capability
\end{tabular}

A B S T R A C T

\begin{abstract}
In future electricity industry transferring high quality of power is essential. In this case, using Flexible AC Transmission System (FACTS) devices is inevitable. FACTS devices are used for controlling the voltage, stability, power flow and security of transmission lines. Therefore, finding the optimal locations for these devices in power networks is necessary. There are several varieties of FACTS devices with different characteristics, deployed for different purposes. Imperialist Competitive (IC) algorithm is a recently developed optimization technique, applied in power systems. IC algorithm is a new heuristic approach for global optimization searches based on the concept of imperialistic competition. In this paper, an IEEE 4-bus system is deployed as a case study in order to demonstrate the results of this novel approach using MATLAB.
\end{abstract}

(C) 2014 Growing Science Ltd. All rights reserved

\section{Nomenclature}

$\theta$

$\gamma$

$\zeta$

$\beta$

B

d

Bus_I

Bus_Type

F_Bus

$\mathrm{P}_{\mathrm{D}}$

$P_{G}$

$\mathrm{QD}_{\mathrm{D}}$

$\mathrm{Q}_{\mathrm{G}}$

$\mathrm{V}_{\mathrm{A}}$

$\mathrm{V}_{\mathrm{M}}$

R
Approaching angle of a colony towards an empire,

Gamma (open parameter),

Zeta (constant co-efficient),

Direction co-efficient,

Total Line Charging Susceptance (p. u.),

Distance,

Bus number (positive integer),

Bus Type ( $1=\mathrm{PQ}, 2=\mathrm{PV}, 3=$ ref, $4=$ isolated $)$,

"'from'” Bus Number,

Real Power Demand (MW),

Real power output (MW),

Reactive Power Demand (MVar),

Reactive power output (MVar),

Voltage Angle (Degrees),

Voltage Magnitude (p. u.),

Resistance (p.u.),

* Corresponding author. Tel: (44/0) 1895265464

E-mail: amirhessam.alikhanzadeh@brunel.ac.uk (A. H. Alikhanzadeh)

(C) 2014 Growing Science Ltd. All rights reserved.

doi: $10.5267 /$ j.ijiec.2014.9.002 
“"to" Bus Number,

\section{Introduction}

In both present and future power systems, transmission network plays significant role in transporting electricity within large distances over national and international borders (Krishans et al., 2007). In recent years by integrating Renewable Energy Sources (RES) in power systems a range of issues such as efficiency, controllability and security have become significantly important. According to the electricity demand growing, these parameters are developing and every year it can be observed that new technologies and methods are introduced in order to minimize the losses and increase the quality of power networks. Principally, power system can transfer the maximum electricity if network can be controlled accurately. In this case, by deploying FACTS devices the transfer capability in power systems can be enhanced.

Rapid developments in power electronics have made different types of FACTS for different purposes. These devices are flexible and assist system operator to improve the power transfer and stability (Belsnes et al., 2011). Considering the existence of high competition in the electricity market, using FACTS devices is essential to achieve the maximum power transfer. In this case, both the amount and type of FACTS devices should be computed to reach the maximum efficiency within a stable network. There are several advantages using FACTS devices in power networks such as (Saravanan et al., 2007):

- Power transfer control,

- Stability control,

- Voltage collapse prevention,

- Power quality improvement,

- Power factor improvement,

- Voltage profile improvement,

- Dynamic stability improvement,

- Load-ability of the transmission lines enhancement, and

- Decreasing in the reactive power losses as a result of increasing the active power transfer.

Allocating and estimating the types and sizes of FACTS devices are the most important area in the transmission network. Indeed, with deploying optimization techniques, maximum efficiency from power networks can be obtained without installing new generators (Saravanan et al., 2007). Based on the FACTS devices' prices and their financial aspects, it is essential to allocate these devices in the optimal locations. For this purpose, initially a mathematical model of the FACTS devices should be considered and then, by using an optimization technique they can be allocated in optimal places. Allocating the FACTS devices is a combinatorial optimization in which both the location and size of these devices should be determined to obtain maximum savings in the power systems investments (Chansareewittaya \& Jirapong, 2010). The aim of this study is to find the best and optimum solution for the proposed problems. In this case a range of evolutionary algorithms have been deployed, which help to achieve the solution. More details are provided in Section 3. Classic mathematic methods have got a range of disadvantages (Hong-Bo \& Shuxia, 2008), since some of these methods consider local optimum as a final answer of the problem.

A novel optimization method called Imperialist Competitive (IC) method is introduced in Section 4. This optimization algorithm is based on the human evolution. The key feature of this evolutionary algorithm comparing to other techniques such as Genetic Algorithm (GA) and Particle Swarm 
Optimization (PSO) is that it finds the optimal placing for the FACTS devices alongside the type and amount for each of them (Shahrazad \& Zobaa, 2013).

Section 5 presents different objective functions with various numbers of constraints that have been taken into consideration in order to illustrate the application of IC algorithm in power industry. It is obvious that by using different objective functions different solutions can be obtained. This is because of the behavior of each objective function. Introducing a range of constrains such as: voltage profile and FACTS compensator sizes is compulsory in the optimization techniques. IC algorithm has essentially proved that it is faster than the other optimization techniques such as GA and PSO. This algorithm can approach the solution with less number of iterations. In this study the IEEE 4-bus system (Deep \& Bansal, 2009) is analyzed and results are presented in Section 6. Finally, Section 7 presents the concluding remarks and future steps.

\section{Study Background}

The aim of deploying power electronic devices in power industry is to enhance the capability of the system in terms of transferring high quality of power to the demand side. FACTS are based on the power electronics converters. With this regard, they are able to create rapid adjustment to control the electrical components. These devices are able to join and connect to the power systems in parallel, series, or a combination of them. Installing extra transmission lines is not always an appropriate solution to increase the power transfer capability. By applying FACTS devices the power transfer and thermal limits of the transmission lines can be controlled in order to assure they are working within their limits.

One of the major parameters, which has special role in operation of both present and future electricity highway systems (EHS), is the power transfer capability (Chansareewittaya \& Jirapong, 2010). Power transfer capability can be defined as an ability of the power network in terms of transferring the power in a specific condition without disturbing the constraints and security of the power systems. This condition depends on the physical constraints and financial issues of the transmission systems. Regarding physical constraints, major issues are related to the security of the power systems. Power transfer constraints can be categorized as a thermal limit of the transmission lines, voltage constraints at bus bars and stability of the power systems (Avramenko, 2005). In this case, power transfer capability of the system has a direct relationship with the economic aspect of the network.

\subsection{Available Transfer Capability}

Available Transfer Capability (ATC) is one of the major functions of the power transfer capability. Principally, it can be defined as the available power transferred in the transmission lines for achieving more profit. This parameter can be obtained by deducting the Transmission Reliability Margin (TRM), Capacity Benefit Margin (CBM), from Total Transfer Capability (TTC) (Rajabi-Ghahnavieh et al., 2009). ATC can be identified as follows:

$A T C=T T C-T R M-$ Existing Transmission Commitments (including CBM)

Transfer capacity and transfer capability have different expressions in the power systems. Transfer capacity represents the loading of the transmission network components such as thermal limit, which is constant and depends on the physical characteristics of the electrical components. However, transfer capability covers mostly the whole system. For maintaining security of supply, this parameter should be calculated and it is essential to assure that this value does not exceed a certain amount (Takasaki, 2006). The power transfer capability between two areas, connected by transmission lines, is greater than the power transfer ability between those areas. This is because of the existence of both physical and electrical limitations of the components in the power network. In spite of transfer capacity, transfer 
capability is an oriented vector. This means the amount of power transfer capability from area A to B is not necessarily equal to the amount of power transfer capability from B to A. FACTS devices can enhance the power transfer capability. In this case, it is vital to examine the impact of FACTS devices in the market during the total transfer capability assessment.

To obtain the total transfer capability all initial conditions of the power system such as estimating the load, distributing the load between the generators, schedule of transfer and operating point of the system should be identified. Total transfer capability is determined according to thermal, voltage, and stability constraints. These constraints can be changed due to different situation such as breakdown of components.

\subsection{FACTS}

FACTS devices are not able to prevent the fault in the system; however, they are able to reduce the inconvenient condition, which occurs due to any fault in the system. For example, cutting off one load from system causes line voltage raise. In this case, FACTS compensators eliminate the extra voltage from the lines and make them stable. Future smart grid operation needs high quality of power. Using FACTS devices decreases the losses and creates high quality of power to the customers. In general FACTS can be divided into four categories:

- Parallel devices

- Series devices

- Series-Series devices

- Series-Parallel devices

List of FACTS devices introduced in this paper are as follows (Tabatabaeiet al., 2011):

\subsubsection{SVC}

Static VAR Compensator (SVC) is an electrical component deployed in high voltage transmission networks. SVC is the parallel compensator, which can be used as a capacitor and variable inductor according in power networks. In fact, SVC is the components that can control the voltage. Therefore, SVC is a kind of generator with zero active power, which compensates voltage at the connected busbar.

\subsubsection{TCSC}

Thyristor-Controlled Series Compensator (TCSC) is a series compensator component, which is used as a capacitor and inductor element in the transmission lines. This device increases the dynamic stability of the power transmission lines and improves the load sharing between the transmission networks.

Table 1 illustrates the characteristics of various types of FACTS devices in order to provide a general overview of their applications in the power systems.

Table 1.

FACTS Devices Specifications

\begin{tabular}{ccccc}
\hline Type & Power Flow Control & Voltage Control & $\begin{array}{c}\text { Dynamic } \\
\text { Stability }\end{array}$ & $\begin{array}{c}\text { Transient } \\
\text { Stability }\end{array}$ \\
\hline SVC & $\checkmark$ & $\checkmark \checkmark \checkmark$ & $\checkmark \checkmark$ & $\checkmark$ \\
STATCOM & $\checkmark$ & $\checkmark$ & $\checkmark \checkmark$ & $\checkmark \checkmark$ \\
TCSC & $\checkmark \checkmark$ & $\checkmark \checkmark \checkmark$ & $\checkmark \checkmark$ & $\checkmark \checkmark \checkmark$ \\
UPFC & $\checkmark \checkmark \checkmark$ & $\checkmark \checkmark \checkmark$ & $\checkmark \checkmark$ & $\checkmark \checkmark$ \\
\hline
\end{tabular}




\subsection{Evolutionary Algorithms}

Optimization method generally is divided into two categories; local optimization and global optimization techniques (Minasian \& Bird, 2013). In general, metaheuristic optimization techniques tend to obtain the global solution; however, they are not always successful or efficient according to the size of the problem. In this case, they may achieve a local optimal solution. These algorithms include GA, PSO, Simulated Annealing, and etc. These algorithms have widely applied in the power systems in order to determine the optimal number and location of FACTS devices (Cai et al., 2004; Majumdar et al., 2006). As presented in (Gerbex et al., 2001) once the number of FACTS devices reaches to the optimal value, installing more FACTS cannot improve the load-ability of the power system.

According to (Panda \& Padhy, 2008) both PSO and GA are inspired by nature, and they can be deployed in optimizing the parameters of a FACTS-based controller. However, PSO has better evolutionary characteristics as it can achieve to the final parameter values in fewer generation comparing to the GA. Considering the computational time, GA can have better performance and achieve to the optimal solution with less iterations.

In fact, many optimization algorithms are based on the nature process. However, considering the social and historical evolution of human have not been considered yet. In fact, this process can be defined as an algorithm that can be faster than other optimization algorithms like GA. More details will be provided in the Section 3. This type of algorithm has considered some part of social-politic of human and by converting this process as a mathematical equation different problems can be solved. This algorithm is also deployed for designing controllers for industrial systems, designing intelligent systems, and finding solution for management problems. Table 2 presents the advantages of IC algorithm over the other evolutionary algorithms such as GA and PSO.

Table 2

FACTS Devices Specifications

\begin{tabular}{|c|c|c|c|c|c|c|}
\hline \multirow[b]{2}{*}{ Method } & \multicolumn{6}{|c|}{ Criteria } \\
\hline & $\begin{array}{c}\text { Speed of } \\
\text { Convergence }\end{array}$ & $\begin{array}{c}\text { Global Search } \\
\text { Ability }\end{array}$ & $\begin{array}{l}\text { Number of } \\
\text { Iterations }\end{array}$ & $\begin{array}{c}\text { Solution } \\
\text { Reliability }\end{array}$ & $\begin{array}{c}\text { Cost Function } \\
\text { Value }\end{array}$ & $\begin{array}{l}\text { Accurancy of } \\
\text { Optimal Value }\end{array}$ \\
\hline$G A$ & $\checkmark \checkmark$ & $\checkmark \checkmark$ & $\checkmark \checkmark$ & $\checkmark \checkmark \checkmark$ & $\checkmark \checkmark \checkmark$ & $\checkmark \checkmark \checkmark$ \\
\hline$I C$ & $\checkmark \checkmark \checkmark$ & $\checkmark \checkmark$ & $\checkmark \checkmark$ & $\checkmark \checkmark$ & $\checkmark \checkmark$ & $\checkmark \checkmark \checkmark$ \\
\hline
\end{tabular}

\section{Methodology}

This algorithm starts with initial selections, which are called countries. They can be the answers for the proposed problem. These countries are as the same as chromosomes in the genetic algorithm and particles in the particle swarm optimization. All these countries are divided into two main groups, imperialist and colony (Atashpaz-Gargari \& Lucas, 2007). After several iterations the algorithm will converge and obtain optimum solution for the problem. This algorithm is based on human evolution history. In this study, the IC algorithm is implemented on a case study with six different analysis and all related results are demonstrated in Section 6.

\subsection{Imperialist Competitive Algorithm Concept}

This algorithm is based on assimilation, imperialistic competition and revolution (Shahrazad \& Zobaa, 2013). IC starts with initial random answer, which in this case called country. Some of these countries are selected in term of less cost function and other main positive parameters. This group is called imperialist and the rest of other countries called colonies. Imperialists will grab the colonies according to their power. After initialization, imperialist competition will be in process. In this case, if one imperialist could not success in competition or increasing its own power, it will be eliminated 
automatically from the competition. Therefore, each empire will not be collapse unless it grabs more colonies. In this process some of the empires will grow and become stronger and some of them collapse and will be eliminated from the competition. This process results in developing empires. Consequently, only one empire will remain and all other colonies will join the last empire. In this case, a kind of convergence can be achieved.

\subsection{Imperialist Competitive Algorithm Implementation}

The countries in the IC algorithm can be defined as follow (Rajabioun et al., 2008):

Country $=\left[p_{1}, p_{2}, p_{3} \ldots p_{N}\right]$

Considering the social-political aspects, the countries can be defined with several features such as culture, language, structure of economy, and etc. Fig. 1 illustrates this performance clearly.

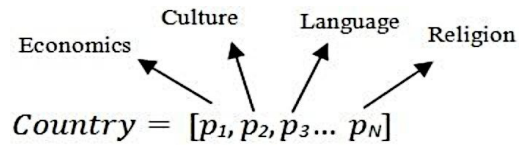

Fig. 1. Characteristics of the Function Variables

During optimization problem, the IC algorithm is looking for the best country with the best features. Realistically, the algorithm needs to find the country with less cost function. Cost of these countries is defined as below:

Cost $=f($ country $)=f\left(p_{1}, p_{2}, p_{3} \ldots p_{N}\right)$

Accordingly, this algorithm looks for the best country and then by making assimilation and imperialistic competition different colonies will be grabbed. Initially, $N_{\text {country }}$ countries are created and $N_{i m p}$ countries from the best countries which have less cost functions are selected as imperialists. The rest, $N_{c o l}$, are the colonies distributed between the empires. Having all the empires, the cost function can be defined as follow:

$C_{n}=c_{n}-\max \left\{c_{i}\right\}$

where, $c_{n}$ is the cost function of $n^{\text {th }}$ imperialist, $\max \left\{c_{i}\right\}$ is the maximum cost between the imperialists, and $C_{n}$ is the normalized cost for the imperialist. Therefore, the empires with more cost are weak empires and will have less normalized costs. According to normalized cost, normalized power of each empire can be defined as follow:

$p_{n}=\left|\frac{C n}{\sum_{i=1}^{N i m p} C i}\right|$

On the other hand, power of one empire depends on the colonies in its authority. Hence, the initial number of colonies of an empire will be:

$N . C_{. n}=\operatorname{round}\left\{p_{n}, N_{c o l}\right\}$

where $N . C_{\cdot n}$ is the initial colonies of one empire, $N_{c o l}$ is the total colonies that exist, and round is the function which gives an integer value in case of having a decimal value. With considering the initial 
position of the all empires, the IC starts. At this stage, the empires try to gather all their colonies in term of different states. Fig. 2 indicates a schematic movement of a colony towards an empire.

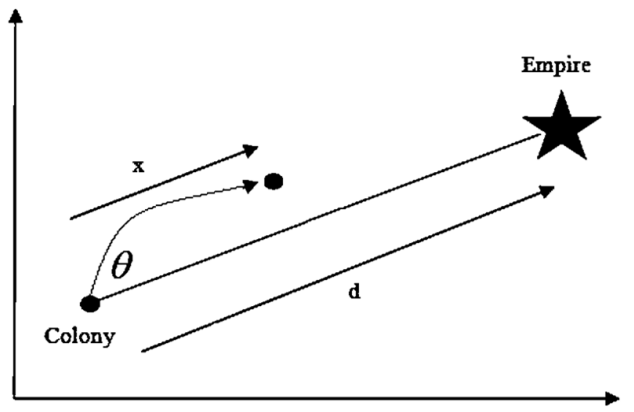

Fig. 2. Movement Process

According to Fig. 2, it can be seen that the colony starts to move towards the empire by $x$ and reaches the new position. The total distance between empire and colony is showed by $d$. The value $X$ is also a random value that follows the below relation:

$X \sim U(0, \beta \times d)$

where $\beta$ is a parameter greater than 1 and close to 2 according to different analysis and simulations. In this case, the $\beta$ value can be assumed to be equal to 2 in order to achieve better results. When $\beta>1$, it can be seen that the colony moves towards the empire in different sides (Rajabioun et al., 2008). By investigating historical data it can be observed that during the assimilation between the imperialists all the expected policies were not according to their favorite plans and sometimes there was a deviation (Rajabioun et al., 2008). This deviation can be define as $\theta$. With this regard, the colonies movement towards the empires might be done with deviation angle as illustrated in Fig. 3.

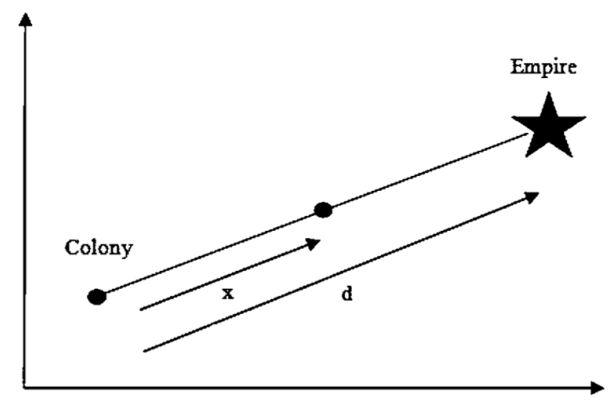

Fig. 3. Colony Movement towards an Empire with Angle

$\theta$ is also a random value and follows the below relation:

$\theta \sim U(-\gamma, \gamma)$

$\gamma$ is the open parameter. By selecting high value of $\gamma$ the colony searches more places around the empire and by choosing small value it will make short distance colony to reach the empire. $\pi / 4$ has been selected as the optimum value (Shahrazad \& Zobaa, 2013). It is important to note that in some cases during the colonies movements towards empires, the colonies may obtain better places than empires. This means that they reach points where the cost function is lower than the empires'. In this condition, colony and empire swap their places and the algorithm continues with new empire. This time the new empire starts to do the assimilation and grab the colonies. 
The total power of imperialist is equal to the power of empire plus some percentage of its colonies power. Hence, the total power of the imperialist is defined as follow:

$$
\text { T.C.n }=\text { Cost }\left(\text { imperialist }_{n}\right)+\zeta \text { mean }\left\{\text { Cost (colonies of empire } \text { en }_{n}\right\}
$$

where, T.C.n is the total cost of $n^{\text {th }}$ empire and $\zeta$ is a value between 0 to 1 . Assuming zero value for $\zeta$ causes the total cost of imperialist becomes equal to the cost of empire itself. However, in optimal cases it can be assumed that $\zeta=0.05$ to achieve reasonable results (Rajabioun et al., 2008).

If any empire could not increase its power and loses the competition, it will be eliminated during the imperialist competition. This elimination will happen gradually.

Hence, the algorithm assumes one empire is about to collapse. In this case, the algorithm selects couple of weakest colonies and makes competition between the empires. The competition between the empires to grab the colony considering the total cost of empires can be modeled. First, the algorithm calculates the total normalized cost:

N.T.C.n $=\max \{$ T.C. $\}-T . C \cdot n$

where N.T.C.n is the total normalized cost of $n^{\text {th }}$ empire. Accordingly, N.T.C.n is equal to the total cost of one empire and N.T.C.n is equal to the total power of that empire. Therefore, an empire with a less cost function is the strongest one. Considering the total normalized cost, the probability of each empire in terms of grabbing the colony can be defined as:

$P_{\mathrm{p} n}=\left|\frac{\text { N.T.C.n }}{\sum_{i=1}^{\text {Nimp N.T.C.i }} \mid}\right|$

The algorithm needs a mechanism such as roulette wheel in the GA in order to allocate the colony according to the empire power. In this study a new mechanism to implement such an algorithm is introduced. One of the advantages of IC algorithm over the GA is that the IC algorithm has got less cost function because it eliminates complicated computation required in the roulette wheel in the GA. In fact, it deletes the cumulative distribution function (CDF) and only needs probability density function (PDF). Based on the probability of grabbing each empire, the algorithm distributes the related colony. $P$ is a vector that can be defined as (Rajabioun et al., 2008):

$P=\left[P p_{1}, P p_{2}, P p_{3}, \ldots, P p_{N(i m p)}\right]$

This vector includes all the probability of the possession values of the empires. Vector $R$ can be created to the same size of vector $P$. The arrays of this type of vector have a random value between 0 and 1 .

$r_{1}, r_{2}, r_{3}, \ldots, r_{N(i m p)} \sim U(0,1), R=\left[r_{1}, r_{2}, r_{3}, \ldots, r_{N(i m p)}\right]$

Hence, $D$ vector can be created as follow:

$D=P-R=\left[D_{1}, D_{2}, D_{3}, \ldots, D_{N(i m p)}\right]=\left[P p_{1}-r_{1}, P p_{2}-r_{2}, P p_{3}-r_{3}, \ldots, P p_{N(i m p)}-r_{N(i m p)}\right]$

The colony is transferred to the empire, which has higher value in the $D$ vector. This part of algorithm is terminated with grabbing the colony by one of the empire. As it was mentioned earlier, during the imperialist competition, weak empires collapse gradually and their colonies are shared between other strong empires. In this case, only one empire will remain and all the colonies will be under its authority and the algorithm will be converged. Fig. 4 presents a general workflow of the IC algorithm. 


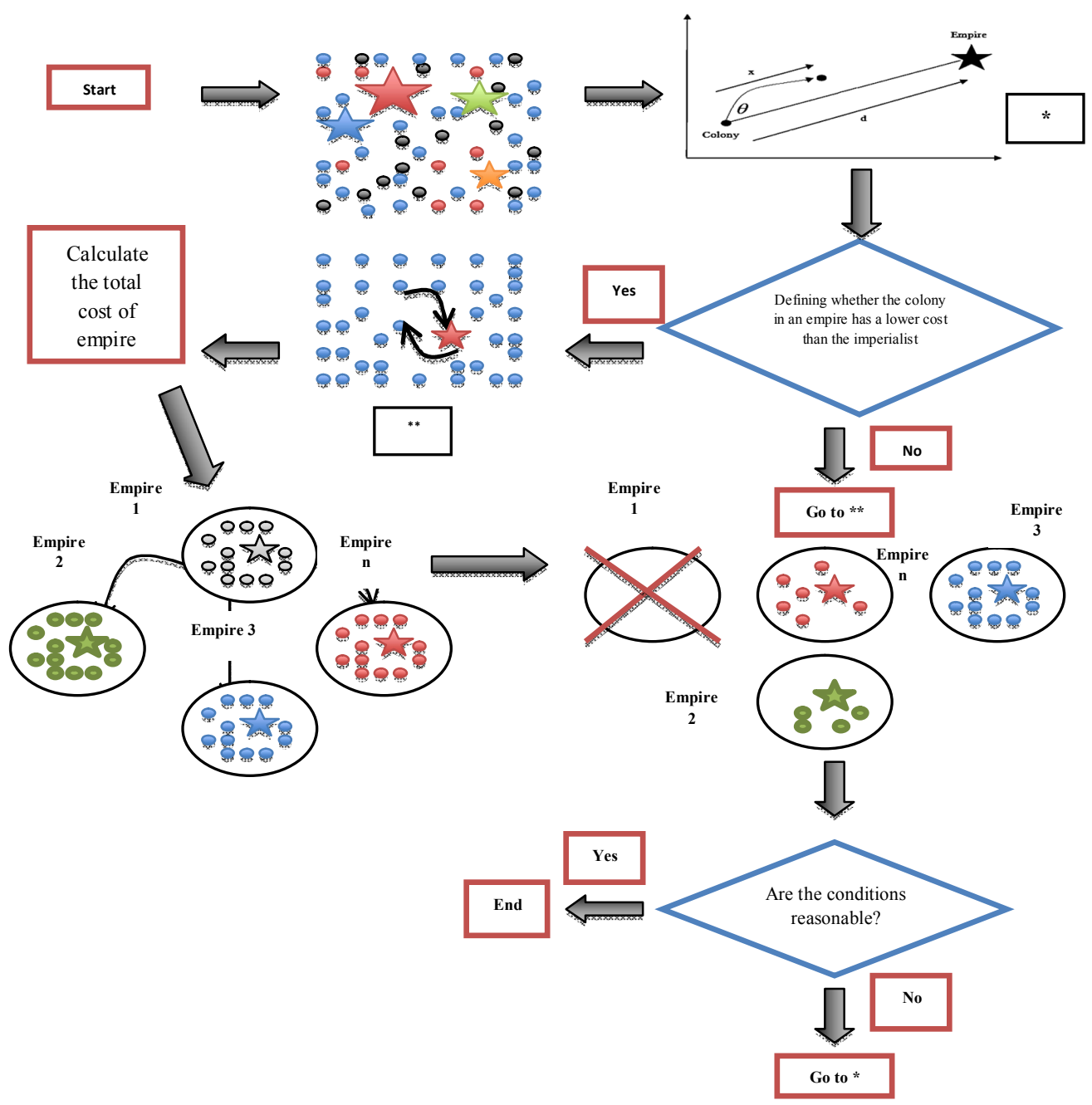

Fig. 4. Schematic Diagram of the IC algorithm

\section{Case Study Related Objective Functions Optimizations}

The IEEE 4-bus system has been considered as a case study. Fig. 5 illustrates a schematic of this network.

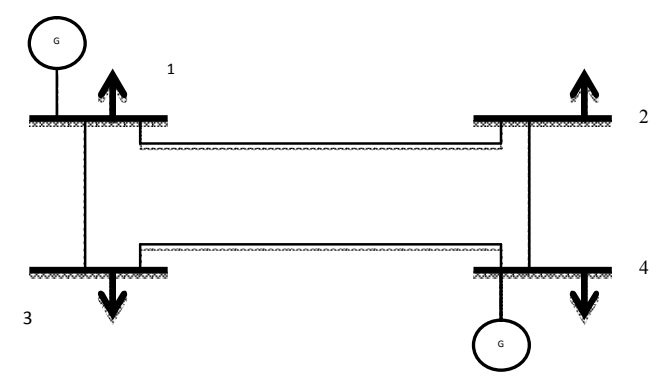

Fig. 5. Single Diagram of the IEEE 4-Bus System

In this case, three objective functions have been involved. As mentioned previously, the size and cost of implementing FACTS devices play significant roles in deployment of these devices in power industry. The objective functions can be defined as follow: 
- $O b j_{1}$ : Minimizing voltage deviation

- $\mathrm{Obj}_{2}$ : Minimizing the FACTS size

- $\mathrm{Obj}_{3}$ : Minimizing the implementation cost

These three objective functions can define as:

$O b j_{1}=V_{d}=\sum_{k \in \Omega}\left(V_{k}-V_{(r e f) k}\right)^{2}$

where, $J_{1}$ is the voltage deviation and $V_{k}$ is the voltage magnitude.

$O b j_{2}=\sum_{j=1}^{N_{\text {units }}} \eta_{j}$

where, $J_{2}$ is the FACTS size, $\eta_{j}$ is the size in MVar of FACTS and $N_{\text {units }}$ is the number of FACTS that should be allocated.

$O b j_{3}=I C=C \times S$

where, $I C$ is the minimum installation cost in $U S \$$ and $C$ is the installation cost function in $U S \$ / k V a r$. According to the data applied from Siemens AG (Hong-Bo \& Shuxia, 2008) the installation costs of TCSC and SVC are:

$\begin{array}{lc}C_{T C S C}=0.0015 S^{2}-0.71305 S+153.75 & U S \$ / k V a r \\ C_{S V C}=0.0003 S^{2}-0.3051 S+127.38 & U S \$ / k V a r\end{array}$

where, $S$ is the operating range of the FACTS devices, which can be defined as:

$S=\left|Q_{\text {post }}\right|-\left|Q_{\text {initial }}\right|$

In this case $Q_{\text {post }}$ is the reactive power in the transmission line after installing FACTS devices and $Q_{\text {initial }}$ is the reactive power in transmission line before installing FACTS devices both in MVAr. Furthermore, other constraints should be defined as:

$\left|V_{i}\right|_{\min } \leq\left|V_{i}\right| \leq\left|V_{i}\right|_{\max }$

$S_{i j} \leq S_{i j \max }, \delta_{i j} \leq \delta_{i j \max }$

where, $\left|V_{i}\right|_{\min },\left|V_{i}\right|_{\max }$ are minimum and maximum voltage magnitudes at bus $i, S_{i j}$ is the apparent power of the line $i$ to $j, S_{i j m a x}$ is the thermal limit of that line, and $\delta_{i j}$ is the difference of phase angels between buses $i$ and $j$. In this study, a range of assumptions have been made as follows:

- The thermal rating has been considered to be equal to $250 \mathrm{MVA}$.

- Minimum and maximum reactive power outputs of the generator have been assumed to be equal to -999 and 999 MVar respectively.

- Minimum and maximum voltage magnitudes have been assumed to be equal to 0.95 and $1.05 \mathrm{pu}$, respectively.

- The $S_{\text {base }}$ has considered being equal to $100 \mathrm{MVA}$.

The total power loss equation is given as:

$P_{l}=\sum\left[V_{i}^{2}+V_{j}^{2}-2 V_{i} V_{j} \cos \left(\delta_{i}-\delta_{j}\right)\right] Y_{i j} \cos \varphi_{i j}$ 
where $\delta_{i}$ is the angle of the voltage at bus $i, Y_{i j}$ and $\varphi_{i j}$ are the magnitude and angle of the admittance of the transmission line between $i$ to $j$, respectively. For computing the TTC the real power generations at bus $i, P_{G i}$, and both real and reactive load powers at bus $i, P_{D i}$ and $Q_{D i}$, which are in function of $\lambda$, should be calculated as follow:

$P_{G i}=P_{G i}+\left(1+\lambda k_{G i}\right)$

$P_{D i}=P_{D i}+\left(1+\lambda k_{D i}\right)$

$Q_{D i}=Q_{D i}+\left(1+\lambda k_{Q i}\right)$

where, $k_{G i}$ and $k_{D i}$ are the constants used to show the rate of changes in the load with various $\lambda \mathrm{s}$. The total transfer capability can be defined as (Shahrazad et al., 2013):

$T T C=\sum_{i=1} P_{D i}\left(\lambda_{\max }\right)-\sum_{i=1} P^{0}{ }_{D i}$

In this case, $P_{D i}\left(\lambda_{\max }\right)$ is the sum of the load in sink area where: $\lambda=\lambda_{\max }$. On the other hand $P_{D i}^{0}$ is the sum of load where: $\lambda=0$. In fact, $\lambda$ is the parameter for increasing load or generation. When $\lambda=0$, there is no power transfer between the areas and when $\lambda=\lambda_{\max }$ there is maximum power transfer.

\section{Experimental Results}

In this section the installation of FACTS devices in terms of single multiple, cost of FACTS devices, load flow, convergence characteristics and P-V curves are investigated. In this case, the number of initial counties is 4 and maximum number of iterations is considered to be 300 . Six analyses are simulated and presented in this paper. Table 3 presents the specifications of the considered case study.

Table 3

Case Study Resistance, Reactance and Susceptance

\begin{tabular}{cccccc}
\hline F_Bus & T_Bus & R $(\mathrm{pu})$ & $\mathrm{X}(\mathrm{pu})$ & $1 / 2 \mathrm{~B}(\mathrm{pu})$ & 0.05125 \\
\hline 1 & 1 & 0.01008 & 0.0504 & 0.03875 & 0 \\
2 & 3 & 0.00744 & 0.0372 & 0.03875 \\
3 & 4 & 0.00744 & 0.0372 & 0.06375 \\
\hline
\end{tabular}

Table 4 indicates a summary of the load flow. In this case, the program analyzes the IEEE 4-bus system using quadratic Newton-Raphson load flow algorithm. Fig. 6 presents the P-V curve before and after installing any FACTS devices. The P-V curve indicates the loading of the power system. To obtain the $\mathrm{P}-\mathrm{V}$ curve in the power system, load is increased slightly and in each step voltage magnitude is analyzed.

Table 4

Load Flow Summary

\begin{tabular}{|c|c|c|c|c|c|c|}
\hline F_Bus & T_Bus & $\mathrm{P}_{\mathrm{ij}}(\mathrm{pu})$ & $\mathrm{Q}_{\mathrm{ij}}(\mathrm{pu})$ & $\mathrm{S}_{\mathrm{ij}}(\mathrm{pu})$ & $\begin{array}{c}\text { Loss } \\
\mathrm{P}(\mathrm{pu}) \\
\end{array}$ & $\begin{array}{c}\text { Loss } \\
\mathrm{Q}(\mathrm{pu})\end{array}$ \\
\hline \multirow{3}{*}{1} & - & 1.368 & 0.835 & 0.160 & - & - \\
\hline & 2 & 0.386 & 0.222 & 0.446 & 0.0022 & -0.089 \\
\hline & 3 & 0.981 & 0.612 & 1.156 & 0.0103 & -0.235 \\
\hline \multirow{3}{*}{2} & - & -1.7 & -1.053 & 1.99 & - & - \\
\hline & 1 & -0.384 & -0.3123 & 0.4955 & 0.0022 & -0.0893 \\
\hline & 4 & -1.31 & -0.741 & 1.50 & 0.0171 & 0.00806 \\
\hline \multirow{3}{*}{3} & - & -2 & -1.239 & 2.352 & - & - \\
\hline & 1 & -0.9708 & -0.6356 & 1.1604 & 0.01031 & -0.02356 \\
\hline & 4 & -1.029 & -0.603 & 1.193 & 0.0183 & -0.03441 \\
\hline \multirow{3}{*}{4} & - & 2.38 & 1.318 & 2.7208 & - & - \\
\hline & 2 & 1.332 & 0.749 & 1.528 & 0.01715 & 0.00806 \\
\hline & 3 & 1.047 & 0.569 & 1.192 & 0.0183 & -0.0344 \\
\hline
\end{tabular}




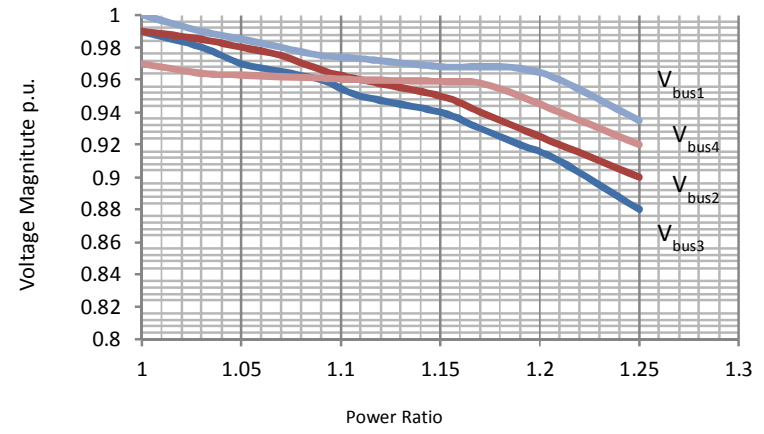

(a)

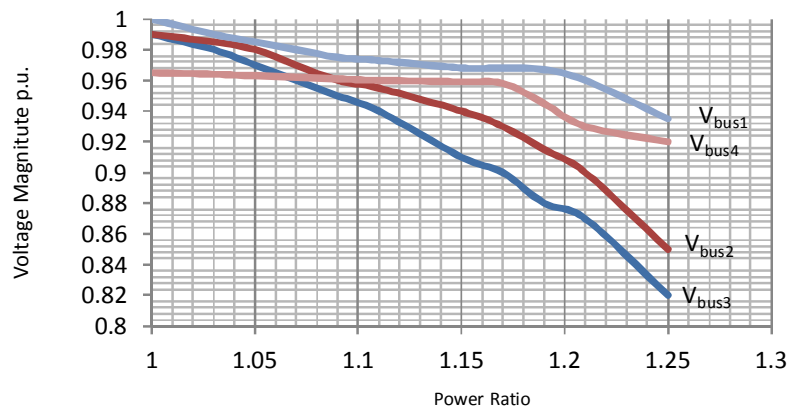

(b)

Fig. 6. P-V Curves Before (a) and After (b) Installing FACTS Devices

According to the behavior of the slope, the voltage collapse point can be obtained; therefore, voltage stability can be analyzed. Fig. 7 illustrates the cost function graph for the SVC and TCSC devices. In this case TCSC has more load-ability characteristics and SVC has less installation cost.

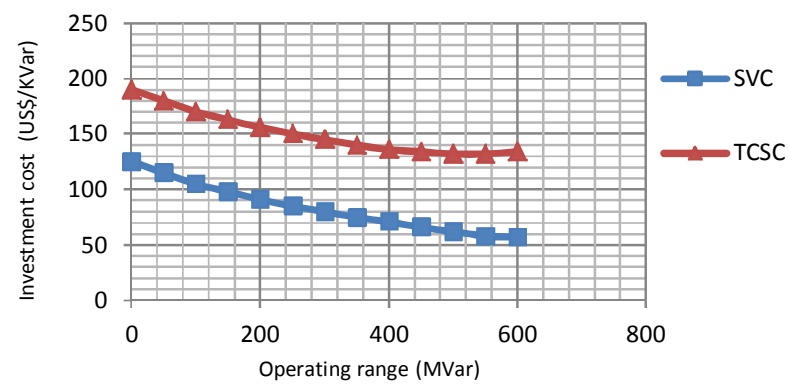

Fig. 7. Investment Cost Curves

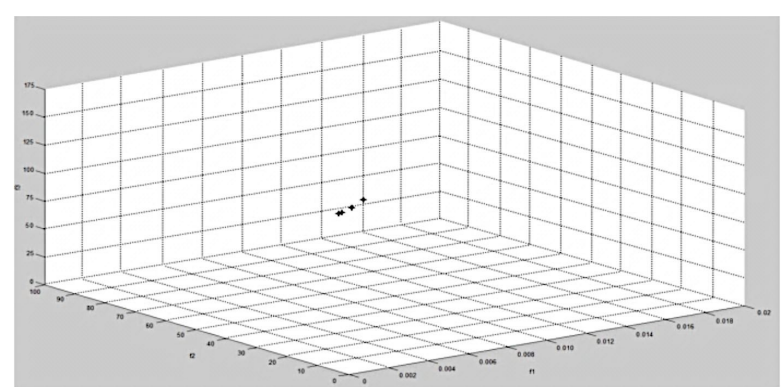

Fig. 8. Solutions' Positions after 4 Iterations

Voltage deviation is one of the major issues, which all industries must also consider. Voltage level can be divided from milliseconds to few seconds. Therefore, installing the FACTS devices in different places can solve the voltage sag problem and supply high quality power in the network. Fig. 8 presents the location of four countries considered in the IC algorithm after four iterations. This paper considers TCSC as a series component in transmission lines and SVC as a parallel component at bus-bars. In this regard, six analyses are performed as follows:

- Allocating one TCSC as a single element,

- Allocating couple of TCSCs,

- Allocating one SVC as a single element,

- Allocating couple of SVCs,

- Allocating a TCSC and SVC at the same time,

- Allocating couple of TCSCs and SVCs at the same time.

It can be identified that by allocating FACTS devices optimally, the losses can be reduced and the system load-ability can be enhanced. Furthermore, it can be observed that by increasing the number of FACTS devices in the transmission system, the installation cost will increase significantly.

\subsection{Allocating one TCSC as a Single Element}

In this analysis only one TCSC has been taken into consideration. Results are presented in Table 5. It can be identified that the amount of losses has been reduced; furthermore, both active and reactive 
powers flowing through the allocated place were increased. Generally imperialist competitive has a good convergence characteristic. This is because of the fact that the algorithm searches the answer by initializing the problem in different groups of area. The speed of convergence is indicated in Fig. 9. It can be understood that the algorithm can be converged after 5 iterations and the optimal place for allocating the FACTS device will be between busses 1-3.

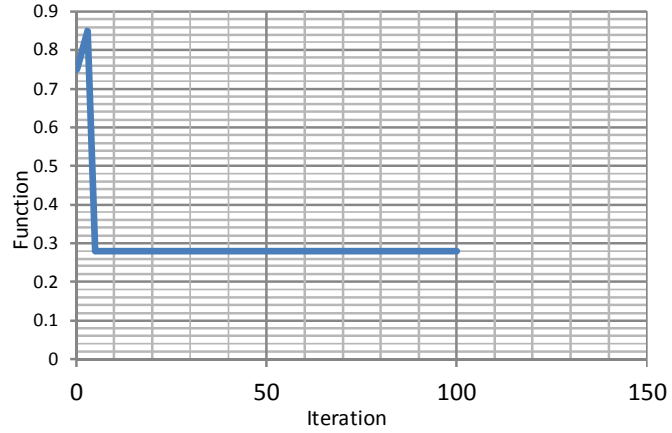

Fig. 9. Convergence Speed with One TCSC

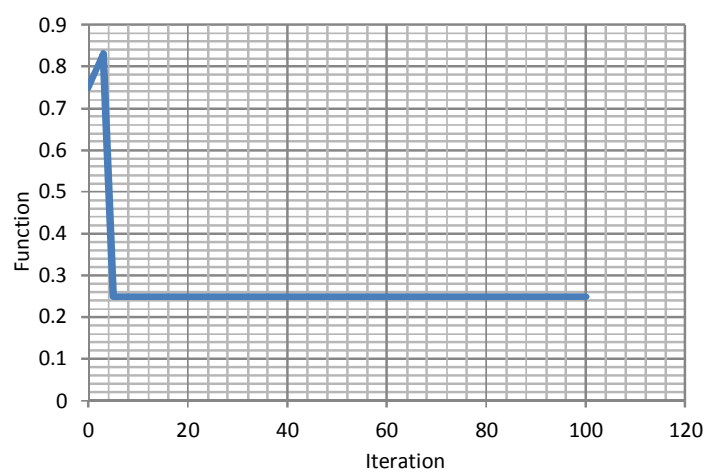

Fig. 10. Convergence Speed with Couple of TCSCs

Table 5

Case Study with One TCSC

\begin{tabular}{|c|c|c|c|c|c|c|c|c|c|}
\hline \multirow{2}{*}{ Case } & \multirow{2}{*}{ Type of FACTS } & \multicolumn{2}{|c|}{ FACTS Location } & \multirow{2}{*}{$\mathbf{P}_{\mathrm{ijb}}(\mathbf{p u})$} & \multirow{2}{*}{$\mathbf{Q}_{\mathrm{ijb}}(\mathrm{pu})$} & \multirow{2}{*}{$\mathbf{P}_{\mathrm{ija}}(\mathbf{p u})$} & \multirow{2}{*}{$\mathbf{Q}_{\mathrm{ija}}(\mathrm{pu})$} & \multirow{2}{*}{$\mathbf{X}_{\mathrm{TCSC}}(\mathrm{pu})$} & \multirow{2}{*}{ Ic $\left(\times 10^{6}\right.$ US\$ } \\
\hline & & F_Bus & T_Bus & & & & & & \\
\hline Single Type & TCSC & 1 & 3 & 0.98 & 0.612 & 1.0072 & 0.603 & -0.64 & 0.0029 \\
\hline
\end{tabular}

\subsection{Allocating Couple of TCSCs}

In this analysis couple of TCSCs have been considered. According to Table 6, it can be identified that the amount of losses were decreased significantly however the cost function increased comparing to installing one TCSC. In this case, the system load-ability increased. Furthermore, both active and reactive powers flowing through the allocated place were increased. In total, two places between busses 1-3 and 3-4 were found, respectively. It is important to note that the installation cost decreases by increasing load-ability of the power network. Speed of convergence with installing two FACTS devices is indicated in Fig. 10. In this case, after 5 iterations the algorithm has been converged.

Table 6

Case Study with Couple of TCSCs

\begin{tabular}{|c|c|c|c|c|c|c|c|c|c|}
\hline \multirow{2}{*}{ Case } & \multirow{2}{*}{ Type of FACTS } & \multicolumn{2}{|c|}{ FACTS Location } & \multirow{2}{*}{$\mathbf{P}_{\mathrm{ijb}}(\mathrm{pu})$} & \multirow{2}{*}{$\mathbf{Q}_{\mathrm{ijb}}(\mathrm{pu})$} & \multirow{2}{*}{$\mathbf{P}_{\mathrm{ija}}(\mathbf{p u})$} & \multirow{2}{*}{$\mathbf{Q}_{\mathrm{ija}}(\mathrm{pu})$} & \multirow{2}{*}{$\mathbf{X}_{\mathrm{TCSC}}(\mathbf{p u})$} & \multirow{2}{*}{ Ic $\left(\times 10^{9} \mathrm{US} \$\right)$} \\
\hline & & F_Bus & T_Bus & & & & & & \\
\hline Single & \multirow{2}{*}{ TCSC } & 1 & 3 & 0.98 & 0.612 & 1.0085 & 0.59 & -0.66 & \multirow{2}{*}{0.0194} \\
\hline Type & & 3 & 4 & -1.029 & -0.603 & -1.036 & -0.583 & -0.32 & \\
\hline
\end{tabular}

\subsection{Allocating one SVC as a Single Element}

This sub-section demonstrates the analysis with installing one parallel SVC in the power network. Subsequently, deploying this FACTS device it can be observed that the installation cost decreased; however, the installation cost by SVC is more than TCSC. In this analysis the power losses also decreased. Both active and reactive powers flowing through the transmission lines are also increased. Furthermore, the load-ability of the system with installing the SVC is enhanced. The optimal place for allocating the FACTS device is bus 3 (Table 7). After 9 iterations the algorithm can be converged (Fig. $11)$. 
Table 7

Case Study with One SVC

\begin{tabular}{|c|c|c|c|c|c|c|c|c|c|}
\hline \multirow{2}{*}{ Case } & \multirow{2}{*}{ Type of FACTS } & \multicolumn{2}{|c|}{ FACTS Location } & \multirow{2}{*}{$\mathbf{P}_{\mathrm{ijb}}(\mathrm{pu})$} & \multirow{2}{*}{$\mathbf{Q}_{\mathrm{ijb}}(\mathrm{pu})$} & \multirow{2}{*}{$\mathbf{P}_{\mathrm{ija}}(\mathrm{pu})$} & \multirow{2}{*}{$Q_{\mathrm{ija}}(p u)$} & \multirow{2}{*}{$\mathbf{X}_{\mathrm{TCsC}}(\mathbf{p u})$} & \multirow{2}{*}{ Ic $\left(\times 10^{6}\right.$ US\$ $)$} \\
\hline & & F_Bus & T_Bus & & & & & & \\
\hline Single Type & SVC & & & -2.00 & -1.239 & -2.052 & -1.201 & -0.48 & 0.0033 \\
\hline
\end{tabular}

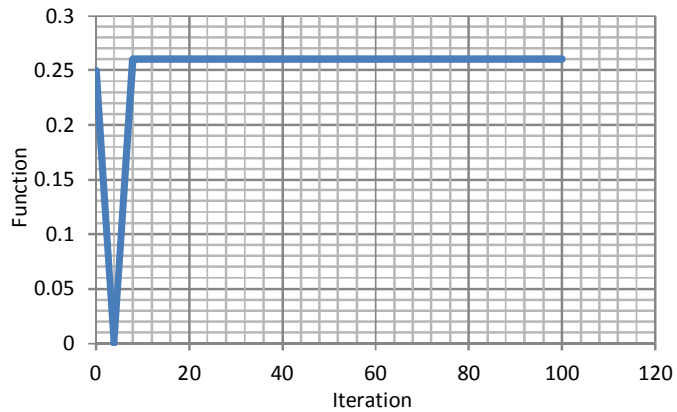

Fig. 11. Convergence Speed with One SVC

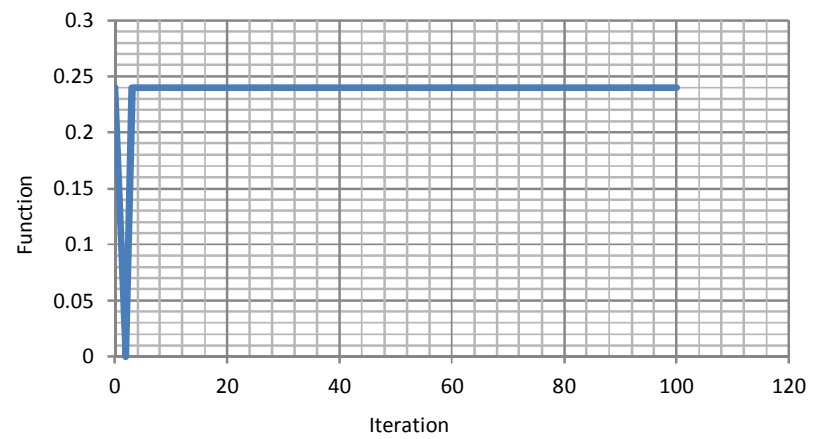

Fig. 12: Convergence Speed with Couple of SVCs

\subsection{Allocating Couple of SVCs}

In this analysis couple of SVCs in the power network have been considered. It can be identified that because of installing more FACTS devices in the transmission network, the installation cost is increased. System load-ability is enhanced and losses are decreased (Table 8). Total installation cost is less than allocating TCSCs in the transmission lines with same number of FACTS devices. The optimal places for allocating FACTS devices are at busses 1 and 3. The IC algorithm is converged after 5 iterations (Fig. 12).

\section{Table 8}

Case Study with Couple of SVCs

\begin{tabular}{|c|c|c|c|c|c|c|c|c|c|}
\hline \multirow{2}{*}{ Case } & \multirow{2}{*}{ Type of FACTS } & \multicolumn{2}{|c|}{ FACTS Location } & \multirow{2}{*}{$\mathbf{P}_{\mathrm{ijb}}(\mathbf{p u})$} & \multirow{2}{*}{$\mathrm{Q}_{\mathrm{ijb}}(\mathrm{pu})$} & \multirow{2}{*}{$P_{\mathrm{ija}}(\mathrm{pu})$} & \multirow{2}{*}{$\mathbf{Q}_{\mathrm{ija}}(\mathrm{pu})$} & \multirow{2}{*}{$\mathbf{X}_{\mathrm{TCSC}}(\mathrm{pu})$} & \multirow{2}{*}{ Ic $\left(\times 10^{9}\right.$ US\$ $)$} \\
\hline & & F_Bus & T_Bus & & & & & & \\
\hline Single & \multirow{2}{*}{ SVC } & \multicolumn{2}{|c|}{1} & 1.368 & 0.835 & 1.40 & 0.78 & -0.62 & \multirow{2}{*}{0.018} \\
\hline Type & & \multicolumn{2}{|c|}{3} & -2.00 & -1.239 & -2.031 & -1.14 & -0.502 & \\
\hline
\end{tabular}

\subsection{Allocating a TCSC and SVC at the Same Time}

This sub-section demonstrates an analysis where different types of FACTS devices are allocated in the power system. With this regard a SVC as a parallel component and a TCSC as a series component have been installed at a bus-bar and on transmission line, respectively. It can be realized that total installation cost increased sharply and total losses are decreased while the system load-ability has increased significantly. Correspondingly, both active and reactive powers flowing through the transmission lines are increased (Table 9). In this case, the optimal place for allocating one SVC is bus 1 , and the best place for allocating one TCSC is between busses 1 and 3. After 13 iterations the IC algorithm can approach the solution (Fig. 13). Hence, by allocating the SVC and TCSC the TTC can increase and this results in reducing the need for constructing new transmission lines.

Table 9

Case Study with a TCSC and SVC

\begin{tabular}{|c|c|c|c|c|c|c|c|c|c|}
\hline \multirow{2}{*}{ Case } & \multirow{2}{*}{ Type of FACTS } & \multicolumn{2}{|c|}{ FACTS Location } & \multirow{2}{*}{$\mathbf{P}_{\mathrm{ijb}}(\mathrm{pu})$} & \multirow{2}{*}{$Q_{\mathrm{ijb}}(\mathrm{pu})$} & \multirow{2}{*}{$\mathbf{P}_{\mathrm{ija}}(\mathbf{p u})$} & \multirow{2}{*}{$\mathrm{Q}_{\mathrm{ija}}(\mathrm{pu})$} & \multirow{2}{*}{$\mathbf{X}_{\mathrm{TCSC}}(\mathrm{pu})$} & \multirow{2}{*}{ Ic $\left(\times 10^{6} \mathrm{US} \$\right)$} \\
\hline & & F_Bus & T_Bus & & & & & & \\
\hline Multi & TCSC & 1 & 3 & 0.98 & 0.612 & 0.9908 & -0.410 & -0.50 & $89 ?$ \\
\hline Type & SVC & \multicolumn{2}{|c|}{1} & 1.36 & 0.835 & 1.405 & -0.249 & -0.382 & 0.72 \\
\hline
\end{tabular}




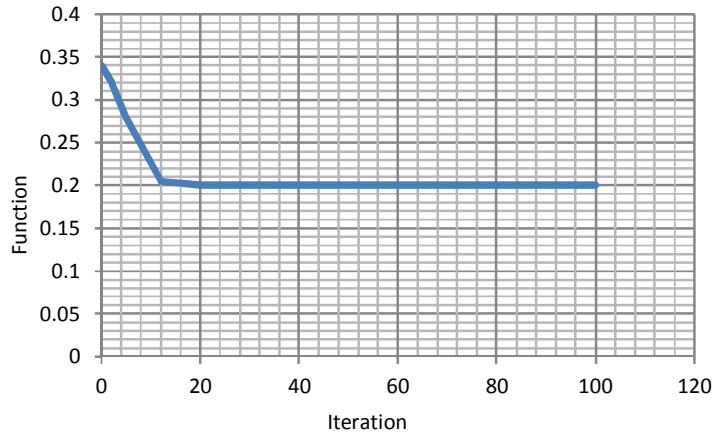

Fig. 13. Convergence Speed with a SVC and TCSC

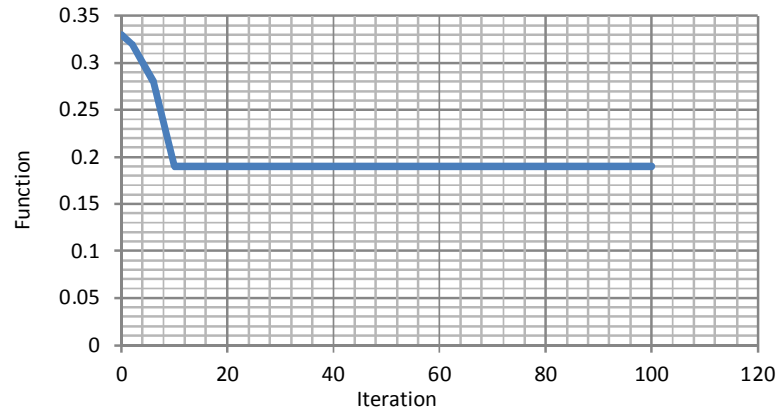

Fig. 14: Convergence Speed with couple of SVC and TCSC Combination

\subsection{Allocating Couple of TCSCs and SVCs at the Same Time}

In this sub-section the algorithm performs optimal analysis for allocating a different types of FACTS devices. In this case, one TCSC and two SVCs have been taken into consideration. As illustrated in Table 10 the installation cost sharply increased. Moreover, the total losses are decreased; on the other hand, the system load-ability increased. Furthermore, by deploying a combination of FACTS devices more optimal results can be achieved over using single type of them. With this respect, the IC algorithm finds 3 optimal places. The parallel FACTS devices can be allocated at busses 1 and 3 , and TCSC will be placed between busses 1 and 3. The algorithm approached the optimal solution after 10 iterations (Fig. 14).

Table 10

Case Study with Couple of TCSCs and SVCs

\begin{tabular}{|c|c|c|c|c|c|c|c|c|c|}
\hline \multirow{2}{*}{ Case } & \multirow{2}{*}{ Type of FACTS } & \multicolumn{2}{|c|}{ FACTS Location } & \multirow{2}{*}{$\mathrm{P}_{\mathrm{ijb}}(\mathrm{pu})$} & \multirow{2}{*}{$\mathrm{Q}_{\mathrm{ijb}}(\mathrm{pu})$} & \multirow{2}{*}{$\mathrm{P}_{\mathrm{ija}}(\mathrm{pu})$} & \multirow{2}{*}{$\mathrm{Q}_{\mathrm{ija}}(\mathrm{pu})$} & \multirow{2}{*}{$\mathrm{X}_{\mathrm{TCSC}}(\mathrm{pu})$} & \multirow{2}{*}{ Ic $\left(\times 10^{9}\right.$ US $\left.\$\right)$} \\
\hline & & F_Bus & T_Bus & & & & & & \\
\hline \multirow{3}{*}{ Multi Type } & TCSC & 1 & 3 & 0.98 & 0.612 & 0.99 & 0.325 & -0.57 & \multirow{3}{*}{5.92} \\
\hline & \multirow{2}{*}{ SVC } & \multicolumn{2}{|c|}{1} & 1.36 & 0.835 & 1.4 & -0.54 & -0.42 & \\
\hline & & \multicolumn{2}{|c|}{3} & -2.0 & -1.239 & -2.04 & -1.173 & -0.63 & \\
\hline
\end{tabular}

\section{Conclusion}

FACTS devices are the most common components used to increase the stability and load-ability of the power networks. Evolutionary algorithms are deployed to allocate FACTS devices in optimum place lead to decrease the losses and improve the voltage profile. Imperialist competitive algorithm is used in this paper to find optimum places of the compensators. Different scenarios are discussed in this paper to demonstrate different approaches. According to the results, it can be identified that using more number of FACTS devices in transmission lines increases the installation cost sharply. Hence, considering the financial terms of FACTS devices are desirable. Imperialist competitive is the latest optimization method recently used in power industry, which can improve both accuracy and speed of the convergence.

\section{Acknowledgement}

The authors would like to thank the anonymous referees for constructive comments on earlier version of this paper. 


\section{References}

Atashpaz-Gargari, E., \& Lucas, C. (2007, September). Imperialist competitive algorithm: an algorithm for optimization inspired by imperialistic competition. IEEE Congress o Evolutionary Computation, 2007. CEC 2007. (pp. 4661-4667).

Avramenko, V. N. (2005, June). Power system stability assessment for current states of the system. In Power Tech, 2005 IEEE Russia (pp. 1-6). IEEE.

Belsnes, M. M., Warland, G., \& Wolfgang, O. (2011, June). Simulating equilibrium prices in oligopoly power markets. IEEE Trondheim in PowerTech, 2011 (pp. 1-8). IEEE.

Cai, L. J., Erlich, I., \& Stamtsis, G. (2004, October). Optimal choice and allocation of FACTS devices in deregulated electricity market using genetic algorithms. In Power Systems Conference and Exposition, 2004. IEEE PES(pp. 201-207). IEEE.

Chansareewittaya, S., \& Jirapong, P. (2010, November). Power transfer capability enhancement with multitype FACTS controllers using particle swarm optimization. In TENCON 2010-2010 IEEE Region 10 Conference (pp. 42-47). IEEE.

Deep, K., \& Bansal, J. C. (2009, December). Optimization of directional overcurrent relay times using Laplace Crossover Particle Swarm Optimization (LXPSO). In Nature \& Biologically Inspired Computing, 2009. NaBIC 2009. World Congress on (pp. 288-293). IEEE.

Gerbex, S., Cherkaoui, R., \& Germond, A. J. (2001). Optimal location of multi-type FACTS devices in a power system by means of genetic algorithms. Power Systems, IEEE Transactions on, 16(3), 537544.

Hong-Bo, S., \& Shuxia, L. (2008, October). The Comparison Between Genetic Simulated Annealing Algorithm and Ant Colony Optimization Algorithm for ASP. In Wireless Communications, Networking and Mobile Computing, WiCOM'08. 4th International Conference on (pp. 1-6). IEEE.

Krishans, Z., Kutjuns, A., \& Kalnins, M. (2007, July). Method of transmission power networks reliability estimation. In Power Tech, 2007 IEEE Lausanne (pp. 1996-1999). IEEE.

Majumdar, S., Chakraborty, A. K., \& Chattopadhyay, P. K. (2009, December). Active power loss minimization with FACTS devices using SA/PSO techniques. International Conference on Power Systems, 2009. ICPS'09. (pp. 1-5). IEEE.

Minasian, A. A., \& Bird, T. S. (2013). Particle Swarm Optimization of Microstrip Antennas for Wireless Communication Systems. IEEE Transactions on Antennas and Propagation, 61(12), 62146217.

Panda, S., \& Padhy, N. P. (2008). Comparison of particle swarm optimization and genetic algorithm for FACTS-based controller design. Applied Soft Computing, 8(4), 1418-1427.

Rajabi-Ghahnavieh, A., Fotuhi-Firuzabad, M., Shahidehpour, M., \& Feuillet, R. (2009). Optimal allocation of available transfer capability in operating horizon. IEEE Transactions on Power Systems, 24(2), 967-975.

Rajabioun, R., Hashemzadeh, F., Atashpaz-Gargari, E., Mesgari, B., \& Salmasi, F. R. (2008, July). Identification of a MIMO evaporator and its decentralized PID controller tuning using colonial competitive algorithm. In be presented in IFAC World Congress.

Saravanan, M., Slochanal, S., Venkatesh, P., \& Abraham, J. (2007). Application of particle swarm optimization technique for optimal location of FACTS devices considering cost of installation and system loadability. Electric Power Systems Research, 77(3), 276-283.

Shahrazad, M., \& Zobaa, A. F. (2013). Optimal allocation of FACTS devices in distribution networks using Imperialist Competitive Algorithm. International Review of Electrical Engineering, 8(5).

Tabatabaei, N. M., Aghajani, G., Boushehri, N. S., \& Shoarinejad, S. (2011). Optimal location of FACTS devices using adaptive particle swarm optimization mixed with simulated annealing. International Journal on Technical and Physical Problems of Engineering (IJTPE), (7), 60-70.

Takasaki, M. (2006, May). Power transfer capability enhancement with UPFC under circumstances of uncertain power flow pattern. In Transmission and Distribution Conference and Exhibition, 2005/2006 IEEE PES (pp. 659-665). IEEE. 